\title{
PEMASARAN IKAN SEGAR AIR TAWAR DI PROPINSI DAERAH ISTIMEWA YOGYAKARTA
}

\section{MARKETING OF FRESHWATER FISH IN SPECIAL REGION PROVINCE OF YOGYAKARTA}

\author{
Sukardi ${ }^{*}$
}

\begin{abstract}
The special region province of Yogyakarta (DIY) has five regencies with different natural resources to support the development of fishery product. Therefore, fishery product especially fish was distributed from surplus regencies to the other regencies which produced less quantity of the product.

The objectives of this study were to know the market structure, market channel, price margin and fluctuation. The study was conducted using analytic discriptive method. Data were collected by survey in 5 regencies in DIY province, covered subjects such as wholesaler, retailer, dealer, farmer (producer) and consumer.

Results of this study indicated that (1) market structure in wholesaler level was oligopoly, but in the retailer level was free market. The retailers had stronger relationship to wholesaler specially for keeping continuity of fish supply, (2) fish market channel and price margin depending on fish species and location of markets, (3) prices fluctuation was determined by supply and demand mechanism. The average price margins in wholesalers and retailer ranged from 10 to 15 and 10 to $20 \%$, respectively, (4) marketing of fresh freshwater fishes were still consentrated in the city and its surrounding area. Comparing with the other regencies in DIY, Yogyakarta Regency (Kotamadya Yogyakarta) had the largest demand for freshwaterfish which was dominated by cat fish (lele dumbo).
\end{abstract}

Key words : Freshwater fish, marketing

\section{Pengantar}

Produksi ikan di Daerah Istimewa Yogyakarta pada tahun 1997 mencapai $8.354,6$ ton, dimana $4.829,2$ ton diantaranya berasal dari budidaya kolam air tawar. Dari produksi tersebut, Yogyakarta masih mendatangkan ikan dari luar DIY sebanyak 22.880, 614 ton setara ikan segar (Anonim, 1997). Besarnya jumlah ikan yang masuk ke Yogyakarta, sebagai salah satu tanda bahwa produksi ikan masih rendah dan belum dapat mencukupi seluruh ikan yang dibutuhkan. Secara umum aliran barang akan berlangsung dari daerah yang surplus produksi ke daerah yang surplus konsumen.
Jumlah barang dan besarnya permintaan akan berpengaruh terhadap harga. Secara umum besarnya harga ditentukan oleh jumlah penawaran dan permintaan. Namun demikian pada keadaan tertentu harga juga dapat dipengaruhi oleh pelaku pasar.

Jumlah barang yang tersedia, selain dipengaruhi oleh besarnya produksi pada suatu daerah juga dipengaruhi oleh aliran barang dari daerah atau tempat lain atau yang disebut dengan proses pemasaran. Harga ditingkat produsen secara langsung akan berpengaruh terdapat pendapatan petani, sedang harga ditingkat konsumen akan berpengaruh terhadap jumlah ikan yang diminta. 
Pemasaran merupakan suatu kegiatan usaha yang mengarahkan pada arus barang dan jasa dari produsen ke konsumen (Swsatha, 1980). Sedang menurut Kotler (1993) pemasaran adalah suatu proses perencanaan dan pelaksanaan konsepsi, penentuan harga, cara promosi, dan distribusi barang dan jasa.

Penelitian ini bertujuan untuk mengetahui pemasaran ikan segar air tawar di Daerah Istimewa Yogyakarta yang meliputi struktur pasar, mekanisme pemasaran, rantai pemasaran, harga dan fluktuasi serta strategi pemasaran. Selain itu dalam penelitian ini dapat mengetahui berbagai hambatan yang terjadi dalam pemasaran ikan segar air tawar.

\section{Bahan dan Metode}

Penelitian menggunakan metode dasar diskriptif analitik dimana pengambilan data primer dilakukan dengan metode survei, yaitu mengumpulkan informasi dari sejumlah sampel. Sampel pasar umum ditentukan secara purposive, sedang sampel pedagang pengecer ditentukan secara random. Sampel pedagang pengecer diambil dari pasar umum yang berada di 4 wilayah kabupaten dan 1 kotamadya yang ada di propinsi DIY. Penentuan sampel saluran pemasaran dilakukan dengan cara perunutan (tracing out), dari data yang diperoleh dari pedagang pengecer di masing-masing pasar. Data sekunder diambil dari berbagai instansi terkait seperti Dinas Perikanan, Dinas Pasar, baik di tingkat kabupaten maupun propinsi. Dari batasan tersebut di atas maka ditentukan 19 pasar umum sebagai tempat penelitian, yang terdiri dari 5 pasar untuk Kabupaten Sleman dan Kotamadya Yogyakarta, 4 pasar masing-masing untuk Kabupaten Bantul dan Kulonprogo serta 1 pasar untuk Kabupaten Gunungkidul. Penelitian dilakukan mulai bulan Oktober 1999 sampai dengan bulan Januari 2000.

Beberapa parameter pemasaran dinalisis secara diskriptif, yaitu meliputi struktur pasar dengan menggunakan derajat kon- sentrasi dari ratio pangsa pasar, ratai pemasaran, harga dan fluktuasi, serta margin pemasaran.

\section{Hasil dan Pembahasan}

\section{Keadaan umum pasar}

Dari hasil inventarisasi jumlah pasar umum di Kotamadya Yogyakarta terdapat 1 pasar kelas II, 8 pasar kelas III, 12 pasar kelas IV dan 12 buah pasar kelas V. Kabupaten Sleman terdapat 24 buah pasar kelas I, 17 pasar kelas II, dan 21 pasar kelas III. Kabupaten Gunungkidul terdapat 3 pasar kelas I, 17 pasar kelas II dan 15 pasar kelas III, dan 33 buah pasar desa. Di Kabupaten Bantul terdapat 29 buah pasar dan beberapa buah pasar desa, sedang untuk Kabupaten Kulonprogo terdapat 35 pasar dengan beberapa pasar desa.

Pedagang pengecer ikan segar air tawar ada di semua pasar umum di wilayah Kotamadya Yogyakarta. Sedang untuk wilayah kabupaten pedagang pengecer ikan segar hanya ada di pasar kelas I (pasar kabupaten), dan beberapa pasar di pinggiran kota. Sebagian besar pedagang ikan belum menempati los (tempat berdagang) secara khusus, kecuali untuk beberapa pasar di Kotamadya Yogyakarta dan Kabupaten Sleman.

Dari hasil indentifikasi diperoleh beberapa pelaku pemasaran yang lain dalam pemasaran ikan segar air tawar, yaitu pedagang pengumpul, agen atau grosir, dan pedagang besar. Pedagang pengumpul biasanya mendatangi para petani produsen, untuk mendapatkan dagangan, dan diantara pedagang pengumpul juga sebagai penyalur sarana produksi seperti benih dan pakan.

Agen atau grosir adalah pedagang yang menerima langsung dagangannya dari pedagang besar, sehingga pedagang ini seolah-olah sekaligus sebagai wakil dari pedagang besar. Agen atau grosir ini terutama terdapat di pasar-pasar di wilayah Kotamadya Yogyakarta, seperti di pasar Kranggan, Demangan, Beringharjo, 
Patuk, dan pasar Kolombo di wilayah Sleman.

Hampir 90\% pedagang besar berasal dari luar Yogyakarta seperti dari Semarang, Pati dan Juwana, dan dan pedagang ini sebagai pemasok utama ikan untuk wilayah Yogyakarta. Setiap pedagang besar biasanya mempunyai pelanggan tetap yang terdiri dari beberapa pedagang pengecer maupun agen atau grosir.

\section{Profil pedagang}

\section{A. Pedagang Pengecer}

Pedagang pengecer ikan segar air tawar di pasar umum 47,3\% adalah perempuan dan $52,7 \%$ adalah laki-laki, dengan usia antara 22-50 tahun. Jika dilihat pendidikannya maka yang berpendidikan SD sebesar 35,4\%, berpendidikan SMP $32,1 \%$, berpendidikan SMU $29,1 \%$ dan sisanya $(3,1 \%)$ telah mengenyam pendidikan perguruan tinggi. Pengalaman mereka sebagai pedagang ikan sebagian besar (lebih dari 60\%) berkisar antara 7-15 tahun, sedang selebihnya mempunyai pengalaman antara 1-22 tahun.

Jika dilihat macam dagangannya maka pedagang ikan segar air tawar, juga sekaligus sebagai pedagang ikan segar air laut, dan hanya $14,5 \%$ juga sebagai pedagang ikan olahan (seperti pindang, ikan asin, terasi dan krupuk ikan).

\section{a. Profil pedagang besar dan pengumpul}

Pedagang besar ada yang berbentuk badan usaha, tetapi ada yang berbentuk usaha perorangan, dan sebagian besar pedagang berasal dari luar DIY. Jika dilihat dari pendidikannya $80 \%$ pedagang berpendikan SMU, dan selebihnya berpendidikan SMP dan SD. Semua pedagang besar selain sebagai pemasok ikan segar air tawar juga merupakan pemasok ikan segar laut. Mereka mendapat pasokan ikan dari pedagang pengumpul atau langsung dari petani untuk ikan air tawar, dan dari pusat pelelangan ikan untuk ikan laut.
Pedagang pengumpul sebagain besar merupakan petani ikan, dan sisanya merupakan pedagang pengecer (20\%). Mereka menyetor ikan langsung ke pedagang pengecer atau juga ke agen atau grosir, dan sebagian besar dari mereka adalah pemasok lele dumbo.

\section{Aktivitas Pemasaran}

\section{A. Struktur pasar}

Rata-rata volume penjualan ikan segar air tawar, yang dijual oleh pedagang pengecer di pasar umum di wilayah propinsi DIY seperti pada Tabel 1 berikut ini.

Tabel 1. Rata-rata volume penjualan ikan yang dipasarkan pedagang pengecer melalui pasar umum

\begin{tabular}{clc}
\hline No. & \multicolumn{1}{c}{ Daerah } & $\begin{array}{c}\text { Volume } \\
\text { Penjualan } \\
(\%)\end{array}$ \\
\hline 1. & Kotamadya Yogyakarta & 42,1 \\
2. & Kabupaten Sleman & 18,2 \\
3. & Kabupaten Bantul & 10,4 \\
4. & Kabupaten Gunungkidul & 14,9 \\
5. & Kabupaten Kulonprogo & 9,6 \\
\hline
\end{tabular}

Dari Tabel 1 dapat diketahui bahwa Kotamadya Yogyakarta mempunyai ratarata penjualan ikan segar air tawar terbesar yang dilakukan oleh pedagang pengecer, disusul oleh pedagang pengecer di kabupaten Sleman dan Gunungkidul. Volume penjualan ikan oleh pedagang pengecer di tiap-tiap pasar tidak menunjukkan perbedaan yang nyata. Pada hari-hari biasa seorang pedagang pengecer dapat menjual ikan segar air tawar antara $5-25 \mathrm{Kg}$. Jumlah pedagang pengecer di tiap-tiap pasar antara 2-6 pedagang, sedang untuk pasar-pasar yang besar dapat mencapai 10 orang. Hampir semua pedagang pengecer mendapat jaminan pasokan ikan dari pedagang besar atau grosir, kecuali pedagang pengecer yang baru.

Secara umum tidak ditemukan hambatan baik secara birokrasi maupun secara teknis terhadap pedagang pengecer baru yang akan masuk ke dalam pasar. Tidak 
adanya jaminan pasokan terhadap pelaku pasar yang baru sebelum pelaku pasar yang baru tesebut masuk dalam kelompoknya, merupakan salah satu bentuk hambatan secara tidak langsung. Penentuan harga ikan di tingkat pedagang pengecer ditentukan oleh pedagang besarnya atau suplyer. Sedang harga di tingkat konsumen, biasanya dilakukan dengan tawar menawar. Dengan beberapa kriteria tersebut di tingkat pedagang pengecer struktur pasar mengarah pada pasar persaingan sempurna.

Pedagang besar biasanya akan memasok ikan langsung ke pedagang-pedagang pengecer atau grosir, dan setiap pedagang besar akan mempunyai kelompok atau pelanggan pedagang pengecer yang berbeda.. Pada pasar-pasar dengan pangsa pasar yang relatif sedikit biasanya hanya dipasok oleh seorang pedagang besar, dan untuk pasar dengan pangsa yang cukup besar biasaya di pasok oleh beberapa pedagang besar. Setiap pedagang besar akan memberikan berbagai kemudahan bagi pedagang pengecernya (misalnya cara pembayaran, bonus), agar mereka tidak berpindah ke pedagang besar yang lain. Hambatan yang terjadi pada pedagang besar baru yang akan masuk ke pasar adalah tidak adanya hubungan dengan pedagang pengecer atau agen, karena pedagang yang ada merupakan kepanjangan tangan dari pedagang besar yang telah ada. Dengan demikian untuk pedagang besar baru yang akan masuk ke pasar, harus membuat saluran pemasaran tersendiri.

Dari hasil perunutan terdapat 5 pedagang besar ikan segar air tawar yang juga sebagai pedagang besar ikan segar air laut. Dengan melihat beberapa parameter tersebut, struktur pasar di tingkat pedagang besar adalah struktur pasar oligopoli.
Agen atau grosir untuk ikan segar air tawar hampir semuanya juga merupakan pedagang pengecer. Agen biasanya mendapat pasokan utama ikan dari pedagang besar, dan juga dari pedagang pengumpul walaupun jumlah dan frekuensinya tidak pasti. Agen biasanya mempunyai pelanggan tetap pedagang pengecer (di pasar lain) dan juga restoran atau rumah makan. Agen biasanya berada di pasar-pasar yang relatif besar, seperti pasar Demangan, Patuk, Kranggan dan pasar Beringharjo. Antara agen dan pedagang pedagang pengecer tidak ada hubungan yang khusus, sebagaimana antara pedagang besar dan pengecer. Namun demikian agen kadang juga memberikan kemudahan bagi pedagang pengecernya (seperti cara pembayaran), namun tidak semua pedagang pengecer diberi kemudahan. Agen dapat dikatakan merupakan kepanjangan tangan dari pedagang besar, sehingga struktur pasar ditigkat ini mengarah pada struktur pasar semi oligopoli.

Jika dilihat dari jenis ikan yang dipasarkan, maka Lele dumbo mempunyai pangsa pasar paling banyak dibanding dengan jenis ikan yang lain. Persentase jenis-jenis ikan yang dipasarkan lewat pasar umum di DIY, seperti pada Tabel 2.

Tabel 2. Jenis ikan yang dipasarkan oleh pedagang pengecer melalui pasar umum

\begin{tabular}{clc}
\hline & & \\
No. Jenis lkan & Jumlah (\%) \\
& & \\
\hline 1. & Lele dumbo & 50,3 \\
2. & Karper/Tombro & 11,6 \\
3. & Nila hitam & 27,8 \\
4. & Nila merah & 2,5 \\
5. & Tawes & 5,1 \\
6. & Bawal dan lain-lain & 2,6 \\
\hline
\end{tabular}

Dari tabel tersebut di atas dapat dilihat bahwa lele dumbo menduduki peringkat 1 
untuk ikan yang paling banyak dijual dan disusul dengan nila hitam, karper/tombro, tawes, ikan lain-lain, dan yang paling sedikit adalah nila merah. Pasokan ikan segar air tawar relatif berfluktuatif dibanding dengan ikan laut, kecuali untuk pasokan lele dumbo dan nila.

\section{B. Mekanisme pemasaran}

Mekanisme pemasaran di tingkat pedagang pengecer dapat dilihat dari aspek pertukaran barang dan sarana penunjang. Pertukaran barang meliputi upaya-upaya pedagang memperoleh barang dagangan dan kegiatan penjualan kepada para konsumen. Sedang aspek sarana penunjang meliputi sarana pembelian (tempat pemasaran, alat, dan bahan bantu), maupun sarana penunjang lain seperti penanganan sisa dan limbah.

Pedagang pengecer ikan segar air tawar biasanya memperoleh pasokan dari pedagang besar, agen (grosir) dan hanya sedikit dari pedagang pengumpul. Pedagang besar biasanya memasok ikan ke pedagang pengecer dan agen di pasarpasar umum dilakukan setiap hari pada pukul 02.00 - 04.00 pagi hari. Sedang pedagang pengecer yang mendapatkan ikan dari agen atau grosir dilakukan mulai pukul 04.00 - 05.00. Untuk pedagang pengecer yang memperoleh ikan dari agen/grosir, dilakukan dengan cara mengambil atau mendatangi di tempat agen.

Aktivitas penjualan ikan di tingkat pedagang pengecer, dilakukan antara pukul $05.00-11.00$. Jika ikan tidak habis terjual beberapa pedagang pengecer dapat mengembalikan ke agen. Namun untuk pedagang pengecer yang mendapat pasokan langsung dari pedagang besar, jika ikan tidak habis terjual maka akan diawet untuk dijual pada hari berikutnya.

Cara pembayaran dari pedagang kecil ke pedagang besar biasanya dilakukan dengan 2 cara, yaitu cara mingguan (pembayaran 1 minggu dibayarkan dalam 1 kali) dan cara harian (pembayaran dilakukan 1 hari kemudian). Sedang cara pembayaran dari pengecer ke agen dilakukan dengan 2 cara yaitu langsung pada saat transaksi, dan yang ke dua dibayar pada siang hari setelah aktivitas penjualan selesai. Pembayaran dari pedagang pengecer ke pedagang pengumpul dilakukan langsung pada saat transaksi, siang hari setelah penjualan atau sehari kemudian.

Cara pembayaran tampaknya digunakan oleh pedagang besar atau agen, untuk mengikat pedagang yang ada di bawahnya, agar tidak pindah ke pedagang besar atau agen yang lain. Dengan cara ini, maka secara tidak langsung seorang pedagang besar atau agen berusaha menguasai pedagang-pedagang pengecer di bawahnya.

Pedagang besar mendapatkan dagangan (ikan) dari pedagang pengumpul atau langsung dari petani, dan sebagian besar pedagang besar berasal dan bertempat tinggal dari luar DIY. Mereka mendapat pasokan ikan dari Jawa Barat (untuk jenis karper), sekitar Jawa Tengah (untuk nila, tawes, lele) dan Jawa Timur (untuk Karper dan lele). Untuk pedagang besar biasanya mempunyai ruangan pendingin (cold storage), dan sarana transportasi dengan mobil box yang didesain secara khusus.

Agen atau grosir sebenarnya merupakan perwakilan dari pedagang besar. Satu pedagang besar biasanya mempunyai beberapa agen dan satu agen mempunyai beberapa pedagang pengecer kecil. Agen atau grosir biasanya mempunyai tempat penyimpanan yang dilengkapi dengan pendingin atau es.

Pedagang pengumpul biasanya adalah pedagang lokal (asal DIY) yang mengambil ikan dari petani dan memasarkan kepada pedagang pengecer maupun warung makan/restoran dan sebagian besar untuk jenis lele dumbo. Pedagang pengumpul mendapatkan ikan dari petani di sekitar Yogyakarta (waduk Sermo, Sleman dan Bantul) dan waduk Gajah Mungkur Wonogiri, Kedungombo dan rawa Jombor. 


\section{Rantai pemasaran}

Rantai pemasaran secara umum menunjukkan pola aliran barang dari produsen ke konsumen. Selain itu rantai pemasaran juga dapat digunakan untuk mengetahui efektivitas kegiatan pemasaran. Rantai pemasaran yang panjang biasanya mempunyai efektivitas yang lebih rendah dibanding dengan pemasaran dengan rantai yang pendek. Secara umum rantai pemasaran ikan segar air tawar melalui pasar umum, seperti tercantum pada skema berikut ini :

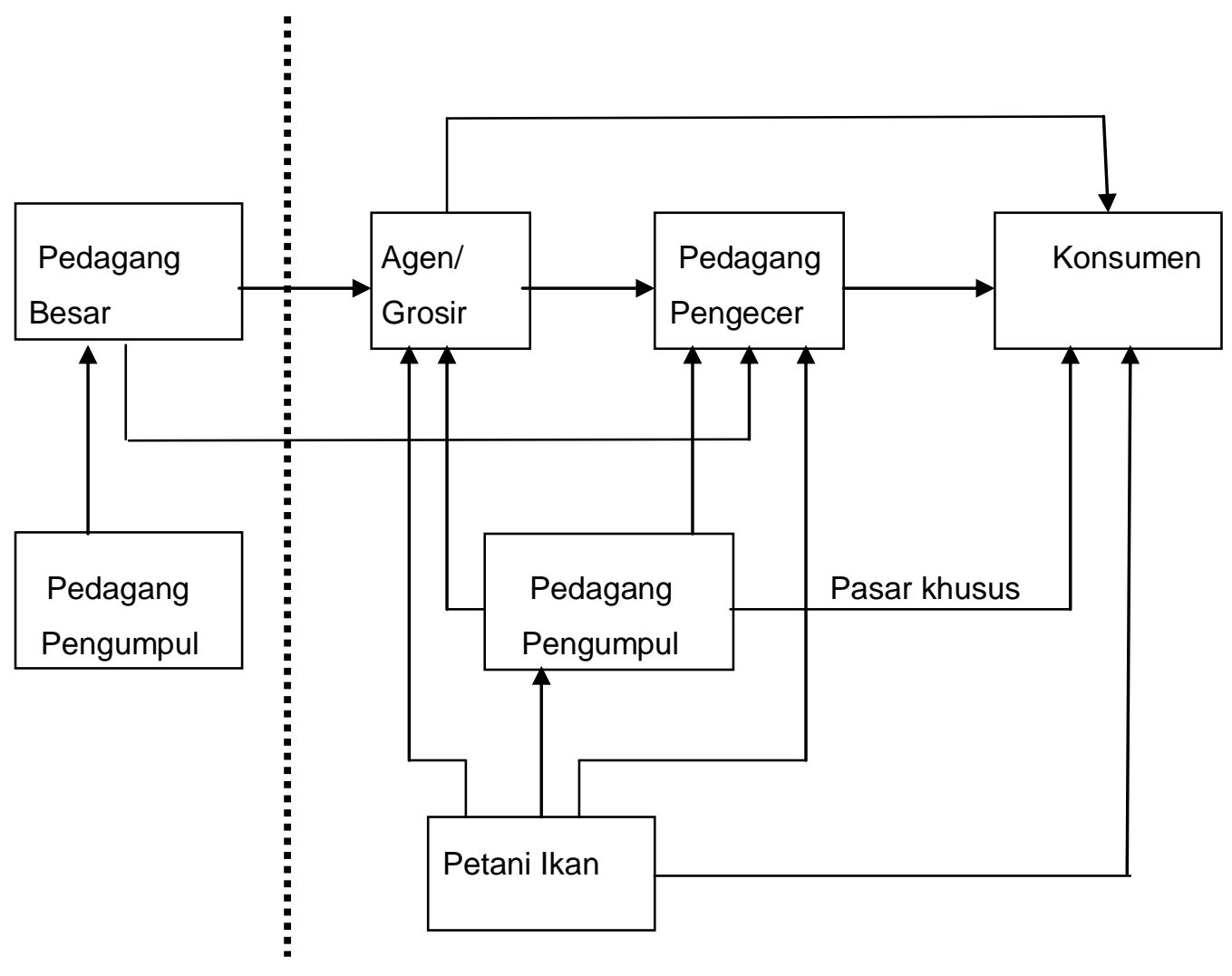

Luar DIY.

Dalam DIY.

Gambar 1. Rantai pemasaran ikan segar air tawar di DIY

Dari Gambar 1 menunjukan bahwa rantai pemasaran ikan segar air tawar di DIY, mempunyai beberapa pola, yaitu :

1. Petani lkan - konsumen

2. Pedagang besar - pedagang pengecer besar - konsumen

3. Pedagang besar - pedagang pengecer kecil - konsumen
4. Pedagang pengumpul - pedagang pengecer kecil - konsumen

5. Pedagang pengumpul - pedagang pengecer besar - konsumen

6. Petani ikan - pedagang pengecer besar - konsumen

7. Petani ikan - pedagang pengecer kecil - konsumen 
8. Pedagang pengumpul - pedagang pengecer besar - pedagang pengecer kecil - konsumen

9. Petani - pedagang pengumpul pedagang pengecer kecil - konsumen

10. Petani - pedagang pengumpul pedagang pengecer besar konsumen

11. Pedagang besar - pedagang pengecer besar - pedagang pengecer kecil - konsumen

12. Petani - pedagang pengumpul pedagang pengecer besar pedagang pengecer kecil konsumen

13. Pedagang pengumpul (luar DIY) pedagang besar - pedagang pengecer kecil - konsumen
14. Pedagang pengumpul (luar DIY) pedagang besar - pedagang pengecer besar - pedagang pengecer kecil - konsumen

Tiap jenis ikan mempunyai pola rantai pemasaran yang berbeda. Secara umum rantai pemasaran untuk jenis Karper, Nila mempunyai rantai pemasaran yang lebih panjang dari pada rantai pemasaran lele dumbo.

Jika dilihat dari asal ikan, maka sebagian besar ikan segar air tawar tidak berasal dari Yogyakarta, melainkan dari daerahdaerah di luar Yogyakarta seperti pada Tabel 3 berikut ini .

Tabel 3. Daerah asal ikan yang dipasarkan pasar umum di DIY

\begin{tabular}{|c|c|c|}
\hline No. & Jenis Ikan & Asal Daerah \\
\hline 1. & Lele Dumbo & $\begin{array}{l}\text { Godean, Moyudan, Banguntapan, Klaten dan Tulungagung } \\
\text { (Jawa Timur) }\end{array}$ \\
\hline 2. & Nila Hitam & $\begin{array}{l}\text { Jawa timur (Lamongan), Semarang (rawa pening), Klaten } \\
\text { (rawa Jombor), waduk Gajah Mungkur, waduk Kedung- } \\
\text { ombo, waduk Sermo (sedikit), Sleman (petani ikan) }\end{array}$ \\
\hline 3. & Nila Merah & Waduk Sermo, Waduk Gajah Mungkur dan Kedungombo \\
\hline 4. & Karper & $\begin{array}{l}\text { Lamongan dan sekitarnya (Jawa Timur), Tasikmalaya, } \\
\text { Semarang, Sleman (petani ikan). }\end{array}$ \\
\hline 5. & Tawes & $\begin{array}{l}\text { Semarang (rawa pening), waduk Gajah Mungkur, Sleman } \\
\text { (petani ikan) }\end{array}$ \\
\hline 6. & Mujahir & Semarang (rawa pening), Sleman \\
\hline 7. & Bawal air tawar & Sleman dan Bantul (petani ikan) dalam jumlah sedikit. \\
\hline
\end{tabular}

Selain jenis ikan, pangsa dan letak pasar juga mempunyai pola rantai pemasaran yang berbeda. Untuk pasar yang mempunyai pangsa yang kecil dan jauh dari kota, biasanya mempunyai rantai pemasaran yang lebih pendek. Hal ini disebabkan pasar dengan pangsa pasar yang kecil tidak terjangkau oleh pedagang besar, sehingga ikan yang dijual hanya berasal dari petani di sekitar. Semakin besar pangsa pasar dan semakin dekat pasar dengan kota, maka pedagang pengecer akan cenderung mengambil ikan dari pedagang besar dengan alasan jumlah dan kesinambungan pasokan terjamin.

\section{Fluktuasi harga dan margin pemasaran}

Seperti barang normal yang lain, harga ikan segar air tawar dipengaruhi oleh besarnya penawaran dan permintaan. Produk ikan hasil budidaya biasanya tidak begitu dipengaruhi oleh musim, sebagaimana produk dari hasil penangkapan. Dari hasil pengamatan, fluktuasi harga ikan air tawar di pasar umum terjadi secara bulanan, musiman dan terjadi tahunan. Fluktuasi harga secara bulanan biasanya terjadi pada waktu padangan (tanggal muda sampai bulan purnama), dimana pada waktu ini pasokan ikan laut turun 
dan menyebabkan naiknya permintaan ikan segar air tawar yang pada akhirnya akan berpengaruh terhadap harga ikan.

Fluktuasi harga musiman, biasanya terjadi pada musim angin barat dimana pasokan ikan segar laut mengalami penurunan akibat sebagian besar nelayan pantai utara tidak dapat melaut. Akibat turunnya pasokan ikan segar laut tersebut, menyebabkan permintaan ikan segar air tawar menjadi naik yang pada akhirnya akan menyebabkan naiknya harga ikan. Fluktuasi harga yang lain yaitu fluktuasi harga yang disebabkan karena meningkatnya permintaan ikan, dan biasanya terjadi pada menjelang hari raya keagamaan, seperti Idul Fitri serta Natal dan tahun baru.

Margin pemasaran adalah selisih harga yang terjadi pada berbagai tingkatan pelaku pasar. Perbedaan harga ini dapat disebabkan karena adanya biaya pemasaran (seperti biaya bahan bantu, transportasi, penyimpanan serta biaya penyusutan alat) dan keuntungan yang diterima oleh pelaku pasar. Besar kecilnya margin antara tingkat pelaku pasar, antar pedagang serta antar jenis ikan adalah tidak sama.

Hasil pengamatan menunjukan untuk harga jual lele dumbo pada pedagang pengecer berkisar antara Rp 7.500 - Rp 8.000 $/ \mathrm{Kg}$, dengan harga beli antara Rp $6.200-$ Rp $7.000,-/ \mathrm{Kg}$. Dengan rata-rata margin sebesar $14,9 \%$. Untuk Karper harga jual di tingkat pedagang pengecer antara Rp 6.500 - Rp 8.000,-/Kg dengan harga beli berkisar antara Rp5.500-Rp7.250,-/Kg, dengan rata-rata margin sebesar $17,7 \%$. Nila (hitam dan merah) yang merupakan ikan yang memiliki pangsa pasar ke 2 setelah lele mempunyai harga jual ditingkat pedagang eceran sebesar Rp 7.000 - Rp 8.000,-/Kg dengan harga beli antara Rp 5.500 - Rp 7.000,-/Kg. Besarnya margin adalah $16,9 \%$.

Di tingkat pedagang di atas pedagang pengecer (pedagang besar, agen atau grosir, suplyer, pedagang pengumpul) margin harga yang terjadi adalah sebesar 10-15\%. Hal tersebut disebabkan semakin besar volume penjualan, biasanya margin harga yang terjadi semakin kecil. Hasil pengamatan juga menunjukkan bahwa semakin panjang rantai pemasaran, maka margin antar pelaku pasar menjadi relatif kecil.

\section{Kesimpulan dan Saran}

\section{Kesimpulan}

a. Struktur pasar ditingkat pedagang besar adalah struktur pasar oligopoli, di tingkat agen atau grosir struktur pasar semi oligopoli, sedang ditingkat pedagang pengecer mengarah ke struktur pasar persaingan sempurna. Ketergantungan pedagang pengecer terhadap pedagang besar atau agen sangat kuat, terutama kaitannya untuk mendapatkan rutinitas pasokan. Hal tersebut merupakan salah satu penyebab sulitnya pedagang besar, agen, pedagang pengumpul baru, untuk masuk ke pedagang pengecer.

b. Rantai pemasaran ikan segar air tawar melalui pasar umum sangat tergantung dari jenis ikan, dan letak pasar. Untuk jenis karper, nila hitam, nila merah mempunyai rantai pemasaran panjang. Sedang untuk jenis lele dumbo mempunyai rantai pemasaran yang pendek.

c. Fluktuasi harga ikan segar air tawar selain dipengaruhi oleh permintaan dan penawaran, juga dipegaruhi oleh fluktuasi pasokan ikan segar air laut. Rata-rata margin harga di tingkat pedagang pengecer sebesar $10-20 \%$, ditingkat pedagang grosir atau agen sebesar $10-15 \%$,dan di tingkat pedagang besar sebesar $10-15 \%$.

d. Pemasaran ikan segar air tawar melalui pasar umum, masih terkonsentrasi pada pusat-pusat perekonomian maupun pusat-pusat 
pengembangan pemukiman, dan belum sampai pada daerah jauh dari kota (pedesaan). Pangsa pasar terbesar untuk ikan segar air tawar masih terpusat pada pasarpasar di wilayah katamadia Yogyakarta dan kabupaten Sleman yang berbatasan dengan kotamadia, dengan jenis ikan yang paling banyak dipasarkan adalah lele dumbo.

\section{Saran}

a. Para produsen (petani ikan) dan pelaku pemasaran ikan segar air tawar perlu memanfaatkan adanya flutuasi pasokan ikan segar laut, untuk memperoleh harga yang relatif tinggi.

b. Perlu tempat pemasaran yang khusus dengan fasilitas untuk mempertahankan mutu, hygienis, representatif, lebih menarik konsumen dan mengurangi persepsi (image) masyarakat bahwa ikan merupakan bahan makan second class

\section{Daftar Pustaka}

Anonim, 1993 a. Agribisnis seri VII. Badan Pendidikan dan Latihan Pertanian. Departemen Pertanian, Jakarta.

Anonim, 1998. Laporan statistisk perikanan propinsi Daerah Istimewa Yogyakarta, tahun 1997. Dinas perikanan propinsi DIY, Yogyakarta, 45 hal.

Anonim, 1998. Laporan tahunan dinas perikanan tahun 1977. Dinas perikanan propinsi DIY, Yogyakarta, 99 hal.
Cristensen, 1989. Teknik dan Kelayakan Ekonomi Pemeliharaan Intensif Ikan Jelawat, dan Ikan Lempan di Dalam Karamba. Persada Utama, Jakarta.

Gunawan, Memed, 1996. Trend perkembangan agribisnis perikanan dan peran penelitian dalam meningkatkan daya saing produk pada pasar global. Prosiding rapat kerja teknis. Pusat Penelitian dan Pengembangan Perikanan. Departemen Pertanian, Jakarta.

Kotler, P. 1993. Manajemen pemasaran. edisi ke-7 Erlangga, Jakarta $599 \mathrm{p}$.

Sadili, D., Haryani, Y.P., Mursidi, Azizi, A.,dan Wahyudi, A., 1991. Pemasaran ikan mas hasil karamba jaring apung di waduk Saguling, Jawa Barat. Bulletin penelitian perikanan darat. Balai penelitian perikanan air tawar, Bogor.

Sadili, D., Azizi A., dan Wahyudi, A., 1992. Manajemen dan pemasaran ikan nila produksi budidaya keramba di Rawa Pening Jawa Tengah. Bulletin penelitian perikanan darat, volume 11. no. 1 Jakarta. 119-127p

Swastha, D.H., 1980. Azas-azas marketing, penerbitan akademi keuangan dan bisnis, Yogyakarta, 328p. 